\title{
Uncertain Analysis of a Stationary Solar Compound Parabolic Concentrator PV Collector System Using Fuzzy Set Theory
}

\author{
Hoe-Gil Lee ${ }^{1}{ }^{1}$ and Singiresu S. Rao ${ }^{2}$ \\ ${ }^{1}$ Department of Engineering and Computer Science, Tarleton State University, Stephenville, TX 76402, USA \\ ${ }^{2}$ Department of Mechanical and Aerospace Engineering, University of Miami, Coral Gables, FL 33146, USA \\ Correspondence should be addressed to Hoe-Gil Lee; hlee@tarleton.edu
}

Received 1 March 2018; Revised 12 August 2018; Accepted 5 September 2018; Published 26 September 2018

Academic Editor: Pallav Purohit

Copyright (c) 2018 Hoe-Gil Lee and Singiresu S. Rao. This is an open access article distributed under the Creative Commons Attribution License, which permits unrestricted use, distribution, and reproduction in any medium, provided the original work is properly cited.

\begin{abstract}
The uncertain analysis of fixed solar compound parabolic concentrator (CPC) collector system is investigated for use in combination with solar PV cells. Within solar CPC PV collector systems, any radiation within the collector acceptance angle enters through the aperture and finds its way to the absorber surface by multiple internal reflections. It is essential that the design of any solar collector aims to maximize PV performance since this will elicit a higher collection of solar radiation. In order to analyze uncertainty of the solar CPC collector system in the optimization problem formulation, three objectives are outlined. Seasonal demands are considered for maximizing two of these objectives, the annual average incident solar energy and the lowest month incident solar energy during winter; the lowest cost of the CPC collector system is approached as a third objective. This study investigates uncertain analysis of a solar CPC PV collector system using fuzzy set theory. The fuzzy analysis methodology is suitable for ambiguous problems to predict variations. Uncertain parameters are treated as random variables or uncertain inputs to predict performance. The fuzzy membership functions are used for modeling uncertain or imprecise design parameters of a solar PV collector system. Triangular membership functions are used to represent the uncertain parameters as fuzzy quantities. A fuzzy set analysis methodology is used for analyzing the three objective constrained optimization problems.
\end{abstract}

\section{Introduction}

Solar CPC PV collector systems are capable of dealing with general situations under concentrated sunlight and issues resulting from higher cell operating temperatures; that is essential in utilizing concentrating systems as solar PV systems. Solar CPCs of PV concentrations have been considered for use in combination with solar cells.

Within solar CPC PV systems, any radiation within the collector acceptance angle enters through the aperture and finds its way to the absorber surface by multiple internal reflections. Improving the efficiency and reducing the cost of these solar collectors is a hot research topic in the field of solar collectors. Winston et al. (1975) [1] suggested a design concept for the compound parabolic concentrator (CPC) intended to collect a greater amount of solar energy using a parabolic reflector by means of increasing the capability of reflecting to the absorber with the widest possible acceptance angles. Abdul-Jabbar et al. (1988) [2] and Kim et al. (2008) [3] studied the CPC collector system with double-axis and single-axis tracking systems and proved the achievement of higher thermal efficiency of the CPC system compared to a stationary CPC solar collector system using experimental and numerical methods. Conversely, Antonelli et al. (2014, 2015) $[4,5]$ investigated the advantages of the solar CPC collector design with an appropriate concentration based on a nontracking system. Antonelli et al. (2016) [6] analyzed thermal heat losses inside CPC solar collectors using the CFD simulation approach with new collector's concepts and materials. To obtain higher and more stable thermal efficiency, Mills et al. (1977) [7] compared two different design concepts for symmetrical and asymmetrical CPC concentrators. In the case of Trupanagnostopoulos et al. (2000) [8], researchers applied two different scales of the CPC units to three smallsize CPC units and a single large-scale CPC unit and found that the smaller CPC unit system had higher performance 
efficiency than the CPC collector system applied to three small pieces of the CPC units.

This CPC concentrator is used with a combination of a photovoltaic and thermal (PV-T) collector to be a solar CPC PV-T system. To improve energy efficiency, the concept of a dual-fluid concentrating photovoltaic thermal (PV-T) solar collector was first introduced by Trupanagnostopoulos (2007) [9]. Aste et al. (2014) [10] studied water as a single fluid for flat plate PV-T collectors, and Proell et al. (2017) [11] proposed the idea that a new conceptual design raises energy efficiency with a low concentrating ratio of CPC reflectors in order to reduce the electrical losses caused by high heating energy in PV efficiency. In the case of Baljit et al. (2017) [12], they researched an upgraded design concept for hybrid concentrating PV-T collectors between air and water as working fluids, leading to improved hybrid system performance using a mathematical modelling approach. Mallick (2004) [13] investigated the design, construction, and tests of an asymmetric CPC collector with different types of PV strings connected. The experiment was implemented both with the $\mathrm{CPC}$ concentrator and without it, and a comparison of the efficiency showed that, at the maximum power point, the $\mathrm{CPC}$ concentrated collector was increased by $62 \%$ compared to a stationary plate PV collector system. Nilsson et al. (2007) [14] proposed a concentration ratio using a PV CPC collector that only requires the tilt angle for seasonal optimal adjustment of the collector rather than a tracking system. Xu et al. (2014) [15] showed an optical analysis of a parabolic trough solar collector using a mathematical model for the purpose of determining the optimal acceptance angle and yearly optimal tilt angle of aperture for maximizing radiation. Haitham et al. (2014) [16] presented a comparative experimental and numerical study on flat photovoltaic strings and symmetric compound parabolic concentrator photovoltaic systems. The research showed that the power output of the PV CPC system is higher than the flat PV string with and without cooling, respectively.

In many real-world problems, the design data, objective functions, and constraints are presented in vague and linguistic terms. However, the optimization problem should be stated in precise mathematical terms. It seems that it is more reasonable to describe a transition progress from absolute possibility to absolute impossibility. The role of fuzzy logic is to establish a bridge between qualitative and quantitative modeling. In this view, as the complexity of a system increases, our ability to make precise and yet significant statements about its behavior diminishes until a threshold is reached beyond which precision and significance become almost mutually exclusive characteristics. For a nonlinear engineering problem, fuzzy set theory is very helpful, and a tool that transforms this linguistic control strategy into a mathematical control method in modeling complex and vague systems. Therefore, the fuzzy logic approach is intended to streamline the decision analysis process and produce an evaluation according to the decision-maker's value system and judgment, while maintaining simplicity and tractability. The fuzzy set theory was introduced by Zadeh over half a century ago (1965) [17]. Nowadays, this theory is being applied to countless fields within and beyond the scope of conventional engineering. Bellman et al. (1970) [18] extended fuzzy set theory to the fuzzy set-based optimization with decision-making in a fuzzy environment. Xiong et al. (2004) [19] presented fuzzy nonlinear programming for mixed-discrete design optimization through hybrid genetic algorithms. They proposed a mixed-discrete fuzzy nonlinear programming approach that combines the fuzzy $\lambda$-formulation with a hybrid genetic algorithm using mathematical techniques for finding the minimum cost design of a welded beam. Eman (2006) [20] investigated a fuzzy approach for a bi-level integer nonlinear programming problem (BLI-NLP), which consists of the higher-level decision-maker (HLDM) and the lower-level decision-maker (LLDM). The paper was focused on two planner integer models and a solution method for solving the problem using the concept of tolerance membership function and a set of Pareto optimal solutions. Liang (2008) [21] studied fuzzy multiobjective production/distribution planning decisions with multiproducts and multitime periods in a supply chain. The paper was focused on a fuzzy multiobjective programming model (FMOLP) with linear membership function to solve integrated multiproduct and multitime period production/distribution planning decision (PDPD) problems with fuzzy objectives. Dubey et al. (2012) [22] and Razmi et al. (2016) [23] studied general procedures for solving multiobjective programming. These papers focused on employing the concept of intuitionistic fuzzy optimization in the process of solving nonlinear programming problems. Randi et al. (2016) [24] used two numerical examples in transportation and manufacturing system areas for solving multi-objective nonlinear programming problems using an intuitionistic fuzzy approach. Jafarian et al. (2018) [25] proposed support for the process of solving multiobjective nonlinear programming problems subject to strict or flexible constraints using a geometric programming technique. This paper includes the suggestion of integral intuitionistic fuzzy sets in the solving procedure and uncertain probabilities in terms of multiple objectives and constraints.

In the collection of the maximum amount of solar energy, the most important considerations in a solar energy system are elevation, declination, and azimuth angles. Although the horizontal face of the solar energy system absorbs the solar energy for maximum performance in summer, the amount of solar radiation is not always maximized due to the particular location and the season as shown Figure 1.

The angle of incidence of the sun's ray on the concentrator is a main concern in collecting as much sunlight as possible. As a high concentration ratio, it is possible to use a multijunction photovoltaic cell with maximum efficiency. Reflector technology can be applied to low concentration photovoltaic module systems to collect sunlight via a solar cell. Determining the angle of the mirrors is dependent on the direction of a photovoltaic module system, which is fixed, and includes inclination of installation and location.

The main concern in a solar CPC PV collector is to maximize amounts of collected solar radiation by the collectors as shown in Figure 2. Thus, the maximizations of annual monthly average incident solar energy and average incident solar energy for the lowest month are determined by the 


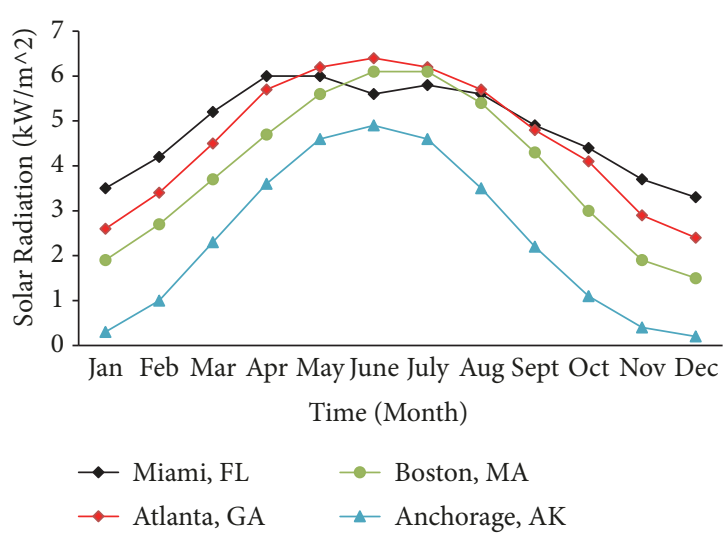

(a) Variation of solar radiation density with respect to month

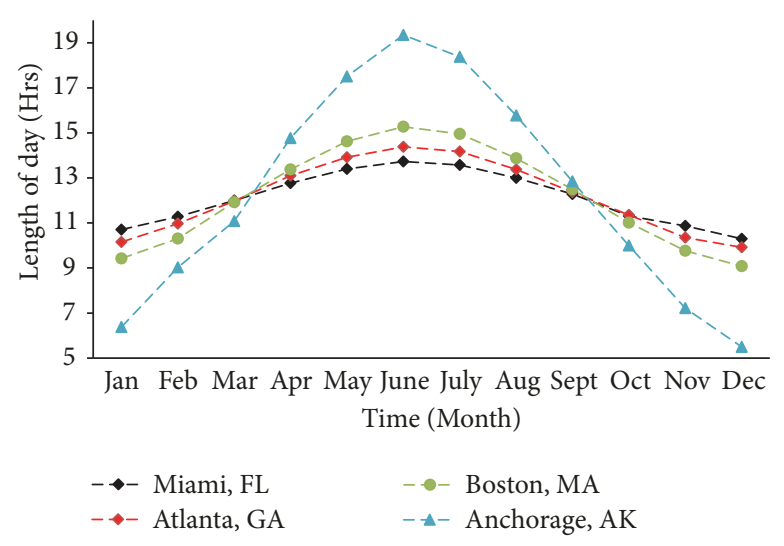

(b) Variation Solar length of days with respect to months

FIGURE 1: Comparison of solar radiation and length in terms of month on horizontal surface by region.

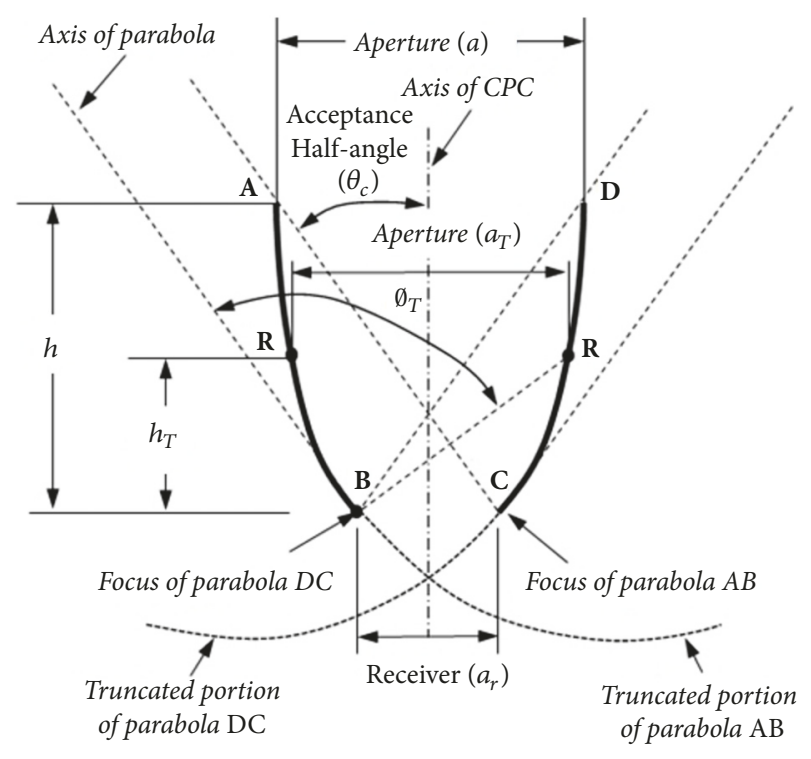

FIGURE 2: Cross section of compound parabolic concentrator and enlarged schematic of receiver.

design of a solar CPC PV collector. The maximization of solar PV performance is essential in the design of any solar collector.

Compound parabolic concentrators (CPCs) are a part of concentrating collectors, which contain parabolic reflectors and planar receivers as shown in Figure 3. CPC applications are dependent on the concentration ratio. This ratio is an area concentration ratio defined as the ratio of the area of the aperture to that of the receiver. A larger concentration ratio indicates a higher temperature, and hence more solar energy can be delivered. Low concentration ratio applications of CPC collectors can be classified into thermal and optical CPC collectors. In the case of thermal CPC collectors, the main concern is to improve the performance by reducing heat losses. In the case of optical CPC collectors, a higher solar cell operating temperature and a nonuniform illumination of the solar cell have the influence of reducing the performance of photovoltaic solar cells.

This study investigates uncertain analysis of a solar CPC PV collector system using fuzzy set theory. The fuzzy analysis methodology is considered suitable for ambiguous problems to predict variations and provides a more complete set of uncertainty information as part of the solution as well as uncertainty only associated with the initial uncertain input data. The fuzzy set theory is concerned with membership of precisely defined sets and is a mechanism for describing objective matters with countable events. Fuzzy set theory is beneficial in three clear ways. First, the theory contributes to realistic analysis of uncertainty since it provides tight bounds on the solutions of possible optimization and presents a method to compute a risk (deviation) as given by the level of the interval uncertainty. Second, a membership function can be established for each of these linguistic values using a certain shape on a certain range as fit for given conditions using triangles, which have been the most popular set shape for approximating nonlinear systems. Last, the fuzzy set theory provides a useful framework for better representing the information about desired projects and explicit benefits in risk modelling for better depicting situational reality. Graphically, a membership function can be represented by a variety of shapes, but it is usually convex. These membership functions can be determined subjectively; the closer an element to satisfy the requirements of a set, the closer its grade of membership is to 1 and vice versa. The fuzzy theory can help design engineers to predict and analyze the performance of objectives with variations in design parameters and/or uncertain input values for uncertainty and design and behavior constraints. For example, the statement "the solar CPC PV collector system generates $100 \mathrm{~kW}$ with a probability of 0.8 " is imprecise because of randomness in the input of uncertain parameters with material properties, manufacturing processes, and environmental conditions of the system. Similarly, in the optimum design of the width of a flat receiver of $a_{r}$, the found length is contained by an upper bound value of $\left(a_{r}^{\max }\right)$ as $a_{r} \leq a_{r}^{\max }$. If $a_{r}^{\max }=0.30$ $\mathrm{m}$, it implies that a design with $a_{r}=0.3 \mathrm{~m}$ is acceptable whereas a design with $a_{r}=0.3001 \mathrm{~m}$ is not acceptable. It 

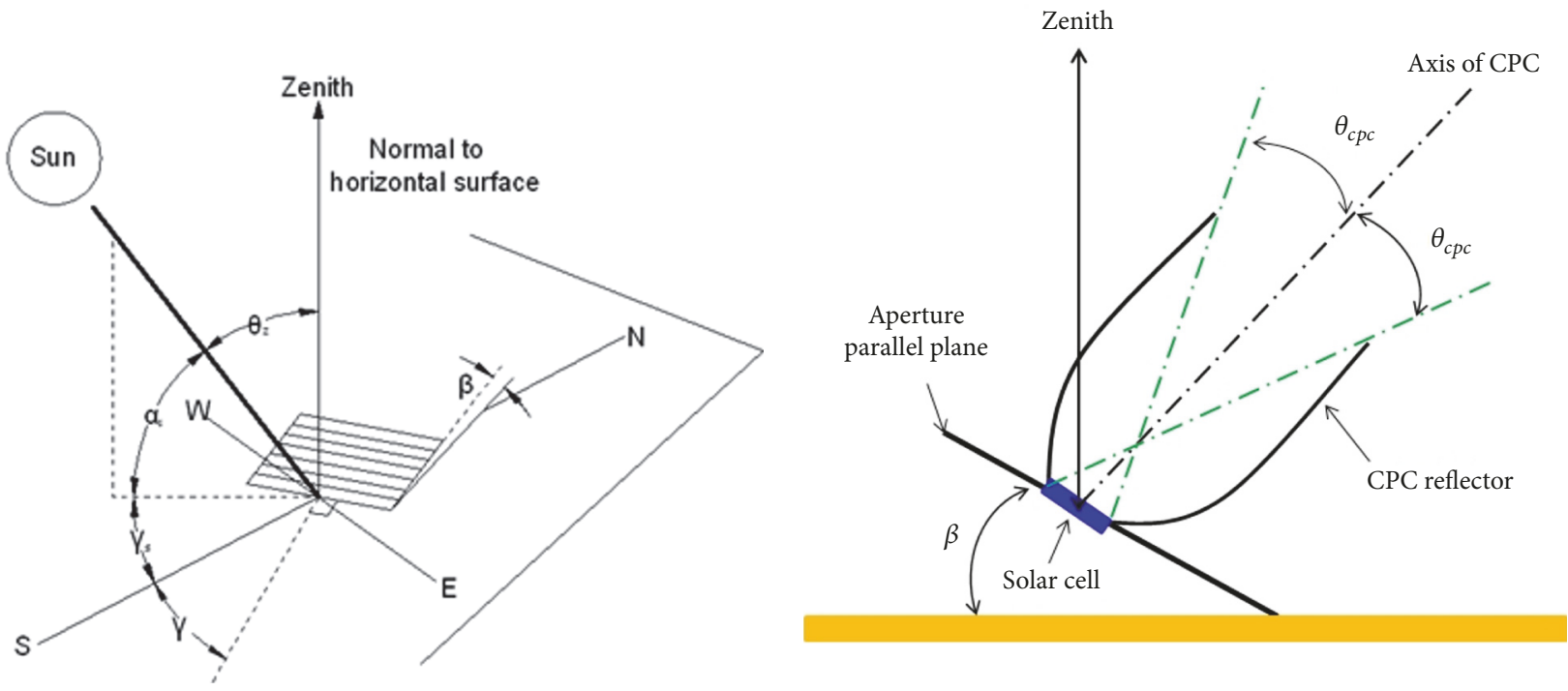

(a) Tilted installation of single CPC PV Collector considering elevation, declination, and azimuth

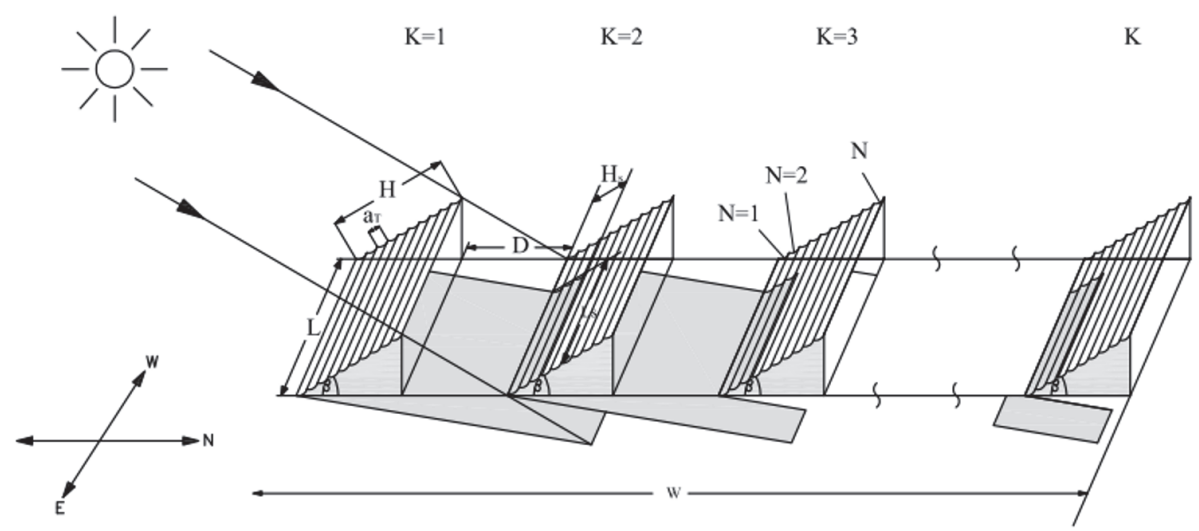

(b) Multiple-row compound parabolic collectors with shading effects in a given area

FIGURE 3: Design process for maximization of a solar CPC PV collector system.

appears that it is more reasonable to have a transition stage from absolute permission to absolute impermissibility. This implies that the constraint is stated in fuzzy terms. Therefore, the fuzzy logic approach is intended to streamline the decision analysis process and produce an evaluation according to the decision-maker's value system and judgment, while maintaining simplicity and tractability. This indicates that membership of an element from the universe in this set is measured by a function that attempts to analyze vagueness and ambiguity and the element of a fuzzy set is mapped to a universe of membership values using a function-theoretic operation. Thus, the uncertain analyses are conducted with the results of three objectives, including the maximization of the annual average incident solar energy, maximization of incident solar energy in winter seasons, and minimization of cost.

\section{Formulation of Single Optimization Problems and Results}

Concentrator CPC PV array systems use reflectors to concentrate sunlight onto PV cells. This technique leads to a reduction in the cell area required for generating a desired amount of power. In a mathematical optimization problem, two different types of values are used for finding the solution: design parameters and variables for design and behavior constraints. They are summarized in Table 1. Design parameters cannot be chosen arbitrarily; rather, they have to satisfy certain specified functions and other requirements. Those restrictions must be satisfied to find an acceptable design performance. In order to determine the suitable performance of the system, the variables for design and behavior constraints should be a represented constraint on the performance of the CPC PV collector system.

In the case of a flat receiver, the geometry of a CPC unit is designed in accordance with two main factors: the acceptance angle of $\theta_{c}$ and the width of flat receiver of $a_{r}$. This controls the concentration ratio, which adjusts a height ratio of $r_{T}$ (the height of truncated CPC/the height of full CPC). The length of aperture of $a$ and the height of $h$ should be considered with the width of flat receiver of $a_{r}$ and the acceptance angle of $\theta_{c}$. For analyzing partial shading effects adjacent to multiple-row collectors, all the solar collectors are considered with a tilt angle $\beta$ in terms of the horizontal 
TABLE 1: Design parameters and variables for design and behavior constraints.

\begin{tabular}{lccc}
\hline Design parameters & & Variables for design and behavior constraints & \\
& CPC unit design & Seasonal characteristic & $s_{b}$ \\
$a_{r}$ & $h$ & $q_{b}$ & $s_{2}$ \\
$\theta_{c}$ & $h_{T}$ & $q_{b}^{\text {sh }}$ & $s_{3}$ \\
$L$ & $\emptyset_{T}$ & $q_{d}$ & - \\
$\beta$ & $a_{T}$ & $\tau_{c p c, b}$ & - \\
$D$ & $\theta_{c p c}$ & $\tau_{c p c, d}$ & - \\
$K$ & $r_{c p c}^{f u l l}$ & $G_{s c}$ & - \\
$N$ & $r_{c p c}^{T}$ & A & - \\
$r_{T}$ & $A_{r e f l e c t o r}$ & - & - \\
- & $W$ & - & - \\
\hline
\end{tabular}

area. The design parameters of the CPC collector are given as

$$
\vec{X}=\left\{\begin{array}{lllllllll}
a_{r} & \theta_{c} & L & \beta & D & K & N & r_{T}
\end{array}\right\}^{T}
$$

The purpose of the solar collector is to collect the maximum solar energy through the system in terms of seasonal demand. Thus, the objective function for maximization is formulated as [26]

$$
\begin{aligned}
Q & =a_{r} \times L \times r_{c p c}^{T} \times N \times\left[q_{b} \tau_{c p c, b}+q_{d} \tau_{c p c, d}\right. \\
& \left.+(K-1)\left(q_{b}^{s h} \tau_{c p c, b}+q_{d}^{s h} \tau_{c p c, d}\right)\right]
\end{aligned}
$$

The objective function for minimization is taken as the negative annual monthly average incident solar energy $\left(f_{1}\right)$, so that the annual average incident solar energy $Q$ is maximized.

$$
f_{1}(\vec{X})=-Q
$$

= annual monthly average incident solar energy

The variation in solar angles has a major impact on the amount of incident solar energy that is collected by a solar collector. The most important design parameters in a solar energy system are elevation, declination, and azimuth angles to collect the maximum amount of solar energy to ensure that winter seasonal characteristics affect winter electricity consumption. Consumption of electricity rises in the winter because the days are shorter and the nights are longer; thus demand for usage of electricity increases. Installation and consumption of power during this season should be a major consideration. Therefore, maximization of incident solar energy should be a factor for the lowest month as the objective function.

$$
f_{2}(\vec{X})=- \text { lowest incident monthly solar energy }
$$

The design parameters and behavior constraints are applied in the case of the optimization problem of maximization of annual average incident solar energy. $r_{c p c}^{T}$ can be derived from using

$$
\begin{aligned}
f & =a_{r}\left(1+\sin \theta_{c}\right) \\
a & =\frac{a_{r}}{\sin \theta_{c}} \\
h & =\frac{f \cos \theta_{c}}{\sin ^{2} \theta_{c}} \\
a_{T} & =\frac{f \sin \left(\emptyset_{T}-\theta_{c}\right)}{\sin ^{2}\left(\emptyset_{T} / 2\right)}-a_{r} \\
h_{T} & =\frac{f \cos \left(\emptyset_{T}-\theta_{c}\right)}{\sin ^{2}\left(\emptyset_{T} / 2\right)} \\
r_{T} & =\frac{\cos \left(\emptyset_{T}-\theta_{c}\right) \sin ^{2}\left(\emptyset_{T} / 2\right)}{\sin ^{2}\left(\emptyset_{T} / 2\right) \cos \theta_{c}} \\
r_{c p c}^{f u l l} & =\frac{1}{\sin _{c}}=\frac{a}{a_{r}} \\
r_{c p c}^{T} & =\frac{a_{T}}{a_{r}}
\end{aligned}
$$

For the constraints, the maximum width of an individual stationary collector should reflect the number of multiplerow CPC reflector units and cannot exceed the aperture length $\left(a_{T}\right)$ of a single collector while considering partial shading effects. This means that the geometry of the CPC units determines the land selected for installation.

$$
K N a_{T} \cos \beta+(K-1) D-W \leq 0
$$

In order to install the solar PV collectors with CPC units from a given land, the side constraints are expressed by

$$
\begin{array}{r}
H=N a_{T} \leq H^{\text {max }} \\
a_{r}^{\text {min }} \leq a_{r} \leq a_{r}^{\text {max }} \\
\theta_{c}^{\text {min }} \leq \theta_{c} \leq \theta_{c}^{\text {max }}
\end{array}
$$




$$
\begin{aligned}
0 & \leq \beta \leq 90 \\
L_{\text {min }} & \leq L \leq L_{\text {max }} \\
D_{\text {min }} & \leq D \\
0 & \leq r_{T} \leq 1 \\
1 & \leq K \leq K_{\text {max }} \\
1 & \leq N \leq N_{\text {max }} \\
1 & \leq r_{c p c}^{T} \leq 3
\end{aligned}
$$

along with a positive integer requirement (constraint) for the number of collectors in a row $N$ and the number of rows of collector $K$.

In examining the role of cost objective function in the optimization problem, there are three components to cost effects: CPC reflectors for concentrating light energy, solar PV cells, and a given installation area. Especially, since the cost of an installation area varies by location, the cost of land of $s_{3}$ is applied to three different values, $1 / 20 / 50 \$ / \mathrm{m}^{2}$, respectively. Thus, the cost objective function of the $\mathrm{CPC}$ collector system can be minimized and given as

$$
\begin{aligned}
& f_{3}(\vec{X})=\text { Cost }=\text { Cost }_{\mathrm{PV}}+\text { Cost }_{\text {reflector }}+\text { Cost }_{\text {land }} \\
& \operatorname{Cost}_{P V}=s_{1} a_{T} L \\
& \text { Cost }_{\text {reflector }}=s_{2} A_{\text {reflector }} \\
& A_{\text {reflector }}=A_{s}\left(1+\sin \theta_{c}\right)\left\{\frac{\cos \theta_{c}}{\sin ^{2} \theta_{c}}\right. \\
& +\log \left[\frac{\left(1+\sin \theta_{c}\right)\left(1+\cos \theta_{c}\right)}{\sin \theta_{c}\left[\cos \theta_{c}+\sqrt{2\left(1+\sin \theta_{c}\right)}\right]}\right] \\
& \left.\quad-\frac{\sqrt{2} \cos \theta_{c}}{\left(1+\sin \theta_{c}\right)^{1.5}}\right\} \\
& \text { Cost }_{\text {land }}=s_{3} L W
\end{aligned}
$$

where $s_{1}$ is the unit cost of cell receiver, $s_{2}$ is the unit cost of reflector, and $s_{3}$ is the unit cost of land.

The optimal design of a solar CPC PV collector system is designed to efficiently collect and concentrate the sun's rays with the acceptance angle. Once the acceptance angle is adjusted, solar CPC PV collector systems are able to concentrate sunlight on the solar cells.

When we use a mathematical optimization technique, we need to provide an initial guess as a starting point for the algorithm. Optimization iteratively improves the initial guess in an attempt to converge to an optimal solution. Consequently, the initial guess of design parameters determines how initial guess converges to a solution within the algorithm. The results of the single-objective optimization problems of the maximization of the annual average incident solar energy $\left(f_{1}\right)$, the maximization of the lowest month incident solar energy $\left(f_{2}\right)$, and minimization of the cost $\left(f_{3}\right)$ are found using the MATLAB program. The MATLAB programming can implement the optimization of a solar CPC PV collector system performance using the program $g a$, which finds mixed-integer values by minimizing a scalar function of several variables starting from an initial set of values of the design parameters. Genetic Algorithms (GA) are suitable for the optimization of complex nonlinear problems to find global optimum solutions with a high probability.

In order to find the single objective optimization of solar CPC collectors, lower and upper bounds, predefined values are illustrated as follows:

$a_{r}^{\text {min }}=0.10(m), a_{r}^{\max }=0.30(m), \theta_{c}^{\text {min }}=25(\mathrm{deg})$, $\theta_{c}^{\max }=90(\mathrm{deg}), L_{\min }=15 \mathrm{~m}, L_{\max }=30 \mathrm{~m}, H_{\text {min }}=0.5 \mathrm{~m}, H_{\text {max }}$ $=2 \mathrm{~m}, D_{\text {min }}=0.8 \mathrm{~m}, K_{\text {max }}=150, N_{\text {max }}=150, \mathrm{P}=80 \%, s_{1}=$ $100 \$ / \mathrm{m}^{2}, s_{2}=20 \$ / \mathrm{m}^{2}, s_{3}=1 / 20 / 50 \$ / \mathrm{m}^{2}, \tau_{c p c, b}=1.0$, and $\tau_{c p c, d}=1.0$

The solar collector is assumed to be installed in a specific location, Miami, Florida (USA) and the stating initial design vectors are given as

$$
\begin{aligned}
\vec{X} & =\left\{\begin{array}{lllllllll}
a_{r} & \theta_{c} & L & \beta & D & K & N & r_{T}
\end{array}\right\}^{T} \\
& =\left\{\begin{array}{lllllllll}
0.10 & 40 & 25 & 40 & 1.0 & 70 & 10 & 0.5
\end{array}\right\}^{T}
\end{aligned}
$$

The results of the single-objective optimization problems of $\mathrm{f}_{1}, \mathrm{f}_{2}$, and $\mathrm{f}_{3}$ are found using the MATLAB program $g a$, which searches mixed-integer values by minimizing a scalar function of several variables starting from an initial set of values of the design parameters along with the initial design. These are listed in Tables 2(a) and 2(b).

In the case of the maximization of annual monthly average incident solar energy $\left(f_{1}\right)$, in order to collect the maximum average incident solar energy during all seasons, the geometric design parameters of the CPC collectors such as $L, \beta, D$, and $K$ dominate the objective function for within a given area. For the single objective function of the maximization of lowest month incident solar energy $\left(f_{2}\right)$, the design parameters have a similar role in ensuring an increase in the amount of solar energy, excluding the value of the truncation ratio $\left(\mathrm{r}_{\mathrm{T}}\right)$ due to the consideration of seasonal characteristics. Lastly, when it comes to minimizing cost $\left(\mathrm{f}_{3}\right)$, the objective function depends on the CPC PV receivers and reflectors and installation land with three different values, $1 / 20 / 50 \$ / \mathrm{m}^{2}$. Therefore, we could observe the value transitions from initial guess to optimum point of each objective finding the feasible solution while satisfying the behavior constraints for each objective function.

The uncertain input parameters of the CPC collector unit have a length of receiver $a_{r}$, an acceptance angle of $\theta_{c}$ truncated at a height ratio $r_{T}$ (the height of truncated $\mathrm{CPC} /$ the height of full $\mathrm{CPC}$ ), dimensions $\mathrm{L} \times \mathrm{W}$ (length $\times$ width), and distance $\mathrm{D}$ between adjacent rows. The solar collector is to be installed in a specific location (Miami, FL), so the altitude $(\mathrm{A})$ and solar constant $\left(G_{s c}\right)$ are considered 
TABLE 2

(a) Initial design and single-objective optimization results (design variables)

\begin{tabular}{|c|c|c|c|c|c|c|c|c|c|}
\hline \multicolumn{10}{|c|}{ Objectives and other outputs } \\
\hline Objectives & & $\begin{array}{c}a_{r} \\
(\mathrm{~m})\end{array}$ & $\begin{array}{c}\theta_{c} \\
(\mathrm{deg})\end{array}$ & $\begin{array}{l}\mathrm{W} \\
(\mathrm{m})\end{array}$ & $\begin{array}{c}\beta \\
(\mathrm{deg})\end{array}$ & $\begin{array}{c}\mathrm{D} \\
(\mathrm{m})\end{array}$ & $\mathrm{K}$ & $\mathrm{N}$ & $r_{T}$ \\
\hline Initial & & 0.10 & 40.00 & 25.00 & 40.00 & 1.000 & 70 & 10 & 0.5000 \\
\hline $\operatorname{Min} f_{1}$ & & 0.11 & 89.54 & 30.00 & 52.98 & 0.806 & 100 & 9 & 0.0036 \\
\hline $\operatorname{Min} f_{2}$ & & 0.17 & 89.82 & 29.98 & 53.79 & 0.807 & 101 & 6 & 0.4160 \\
\hline \multirow{3}{*}{$\operatorname{Min} f_{3}$} & $s_{3}=1$ & 0.11 & 25.62 & 28.81 & 21.69 & 0.802 & 76 & 4 & 0.6136 \\
\hline & $s_{3}=20$ & 0.14 & 25.03 & 29.37 & 21.26 & 0.800 & 69 & 4 & 0.2622 \\
\hline & $s_{3}=50$ & 0.25 & 89.97 & 29.48 & 20.35 & 0.801 & 64 & 4 & 0.0012 \\
\hline
\end{tabular}

(b) Initial design and single-objective optimization results (objective functions and other outputs)

\begin{tabular}{|c|c|c|c|c|c|c|}
\hline \multicolumn{7}{|c|}{ Objectives and other outputs } \\
\hline \multicolumn{2}{|c|}{ Objectives } & cpc ratio & $\begin{array}{c}\mathrm{f}_{1} \\
\left(10^{6} \times W\right)\end{array}$ & $\begin{array}{c}\mathrm{f}_{2} \\
\left(10^{6} \times W\right)\end{array}$ & $\begin{array}{c}\mathrm{f}_{3} \\
\left(10^{6} \times W\right) \\
\end{array}$ & $\begin{array}{l}f_{3} / f_{1} \\
(\$ / W)\end{array}$ \\
\hline \multicolumn{2}{|l|}{ Initial } & 1.4450 & -1.2675 & -1.0230 & 0.5517 & 0.4353 \\
\hline \multicolumn{2}{|l|}{$\operatorname{Min} f_{1}$} & 1 & -1.3790 & -1.1462 & 0.7190 & 0.5214 \\
\hline \multicolumn{2}{|l|}{ Min $f_{2}$} & 1 & -1.3778 & -1.1480 & 0.7257 & 0.5267 \\
\hline \multirow{3}{*}{$\operatorname{Min} f_{3}$} & $s_{3}=1$ & 2.1921 & -1.1032 & -0.8421 & 0.3063 & 0.2776 \\
\hline & $s_{3}=20$ & 1.7963 & -1.1032 & -0.8833 & 0.4007 & 0.3632 \\
\hline & $s_{3}=50$ & 1 & -1.1032 & -0.8927 & 0.4689 & 0.4250 \\
\hline
\end{tabular}

as uncertain input parameters. The uncertain input design parameters are

$$
\overrightarrow{\mathrm{S}}=\left\{\begin{array}{c}
a_{r} \\
\theta_{c} \\
L \\
\beta \\
\mathrm{D} \\
r_{T} \\
A \\
G_{s c}
\end{array}\right\}\left\{\begin{array}{l}
S_{1} \\
S_{2} \\
S_{3} \\
S_{4} \\
S_{5} \\
S_{6} \\
S_{7} \\
S_{8}
\end{array}\right\}
$$

For the purpose of analyzing the uncertainty of the solar CPC PV collector system, fuzzy confidence intervals are needed particularly to conduct the problems of optimization with a fuzzy objective function or fuzzy constraints and investigate some ambiguities in fuzzy set theory. $\pm 1 \%, \pm 2 \%, \pm 3 \%, \pm 4 \%$, and $\pm 5 \%$ of the fuzzy confidence intervals are applied to the solar CPC PV collector system for observing the deviations of three single-objective problems with respect to the fuzzy interval levels from each crisp value.

\section{Fuzzy Set Analysis}

The mapping of uncertain input onto an uncertain response is called fuzzy set analysis. Fuzzy set theory provides gradual membership from the domain of quantitative and precise phenomena to vague, qualitative and imprecise conceptions. A fuzzy member can be represented using the concept of a range of interval confidence. The fuzzy set theory allows for gradual membership functions in relation to the set. This gradual membership is explained by a membership function. Membership in a classical subset $\mathrm{A}$ of $\mathrm{X}$ can be defined as a characteristic function $\mu_{A}$ from $\mathrm{X}$ to $[0,1]$ as

$$
\mu_{A}(x)= \begin{cases}1 & \text { if } f x \in A \\ 0 & \text { if } f x \notin A\end{cases}
$$

A set A is called a fuzzy set if the valuation set is allowed to be the real interval $[0,1]$. The fuzzy set $\mathrm{A}$ is completely characterized as

$$
\mathrm{A}=\left\{\left(x, \mu_{A}(x)\right), x \in X\right\}
$$

The membership function, $\mu_{A}(x)$, quantifies the degree of membership of the elements $x$ in A. The closer the value $\mu_{A}(x)$ is to 1 , the more $x$ belongs to A. A is a fuzzy subset of $\mathrm{X}$ that has no sharp boundary. When $\mathrm{X}$ is a finite set $\left\{x_{1}, x_{2}, \ldots, x_{n}\right\}$, a fuzzy set on $\mathrm{X}$ can be defined as

$$
\mathrm{A}=\mu_{A}\left(x_{1}\right)+\mu_{A}\left(x_{2}\right)+\cdots+\mu_{A}\left(x_{n}\right)=\sum_{i=1}^{n} \mu_{A}\left(x_{i}\right)
$$

The extension principle plays a critical role in translating setbased concepts into fuzzy-set counterparts for transforming fuzzy sets through membership function. The $\alpha$-level method is used for analyzing fuzzy sets. All fuzzy input parameters are discretized using a number of $\alpha$-levels. In the $\alpha$-level approach, the optimum solution is regarded as one that has at least a certain degree of membership in the fuzzy feasible domain. The $\alpha$-cut of $\alpha$-level set of fuzzy set A is a set consisting of those elements of the universe $\mathrm{X}$ whose 


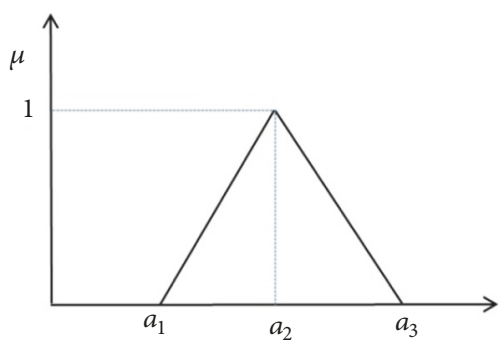

Figure 4: Triangular fuzzy number.

membership values exceed the threshold level $\alpha$ and can be expressed as

$$
A_{\propto}=\left\{\frac{x}{\mu_{A}(x)} \geq \alpha\right\}
$$

The membership function associated with a fuzzy set can be explained by its triangular shape. It is a fuzzy number represented with three points as $\mathrm{A}=\left(a_{1}, a_{2}\right.$, and $\left.a_{3}\right)$ and is shown in Figure 4. This representation is interpreted as membership functions and defined as

$$
\mu_{A}(x)= \begin{cases}0 & \text { if } x<a_{1} \\ \frac{x-a_{1}}{a_{2}-a_{1}} & \text { if } a_{1} \leq x \leq a_{2} \\ \frac{a_{3}-x}{a_{3}-a_{2}} & \text { if } a_{2} \leq x \leq a_{3} \\ 0 & \text { if } x>a_{3}\end{cases}
$$

The interval arithmetic method is used for applying the interval confidence of lower and upper bound values of uncertain input parameters and can be defined by the extension principle. The extension principle can be used to extend the four standard arithmetic operators: addition, subtraction, multiplication, and division to be used with a fuzzy number. The lower and upper bound values are given by $y_{i}=y_{i} \pm \Delta y_{i}$; $j=1,2, \ldots i . y_{i}$ is the base value and $\Delta y_{i}$ means the tolerance on $y_{i}$. A real number $y$ is equivalent to an interval range [y, $y$ ], which has zero tolerance. The interval arithmetic method is used for creating the lower and upper bound values with the tolerance using interval arithmetic operations "•" $(+,-, \times, \div)$. Thus, the interval arithmetic value of $\mathrm{X} \bullet \mathrm{Y}$ can be formed from two intervals $\mathrm{X}=[\underline{\mathrm{X}}, \bar{X}]$ and $\mathrm{Y}=[\underline{\mathrm{Y}}, \bar{Y}]$. The basic interval arithmetic operations are expressed as

$$
\begin{aligned}
& \text { Addition: } \mathrm{X}+\mathrm{Y}=[\underline{\mathrm{X}}+\underline{\mathrm{Y}}, \overline{\mathrm{X}}+\overline{\mathrm{Y}}] \\
& \text { Subtraction: } \mathrm{X}-\mathrm{Y}=[\underline{\mathrm{X}}-\overline{\mathrm{Y}}, \overline{\mathrm{X}}+\underline{\mathrm{Y}}] \\
& \text { Multiplication: } \mathrm{X} \\
& \quad \times \mathrm{Y}=\min .[\underline{\mathrm{X}} \times \underline{\mathrm{Y}}, \underline{\mathrm{X}} \times \overline{\mathrm{Y}}, \overline{\mathrm{X}} \times \underline{\mathrm{Y}}, \overline{\mathrm{X}} \times \overline{\mathrm{Y}}], \\
& \max .[\underline{\mathrm{X}} \times \underline{\mathrm{Y}}, \underline{\mathrm{X}} \times \bar{Y}, \bar{X} \times \underline{\mathrm{Y}}, \overline{\mathrm{X}} \times \bar{Y}] \\
& \text { Division: } \mathrm{X} \div \mathrm{Y}=[\underline{\mathrm{X}}, \bar{X}] \times\left[\frac{1}{\bar{Y}}, \frac{1}{\mathrm{Y}}\right]
\end{aligned}
$$

Solar CPC PV collector systems are analyzed through fuzzy set theory using a membership function in a fuzzy confidence interval. The deviation is determined by the difference between the membership function of the actual Solar CPC PV collector system performance and the crisp value of the PV system performance obtained using interval-valued fuzzy set and the membership function of the deterministic optimization of solar CPC PV collector systems. The membership function of the actual performance of a solar cell places Lb (low bound) for the left and Ub (upper bound) for the right segment. The membership function of the crisp performance of a solar PV system is expressed as CP (crisp performance). The left side and right side errors can be calculated as

$$
\begin{aligned}
\Delta \mathrm{Lb} & =\mathrm{CP}-\mathrm{Lb} \\
\text { and } \Delta \mathrm{Ub} & =\mathrm{CP}-\mathrm{Ub}
\end{aligned}
$$

The deviation of both sections can be derived from

$$
\begin{aligned}
\Delta \mathrm{Lb}, \%= & \left|1-\frac{L b}{C P}\right| \\
& \times 100 \text { (deviation in lower bound section) }
\end{aligned}
$$

and

$$
\begin{aligned}
& \Delta \mathrm{Ub}, \% \\
& =\left|1-\frac{U b}{C P}\right| \\
& \quad \times 100(\text { deviation in upper bound section })
\end{aligned}
$$

Thus, the deviation as the percent absolute error with respect to solar PV system performance is calculated in both the lower bound and upper bound sections from the result of the crisp value of solar PV system performance. The $\alpha$-cut interval levels of $0,0.25,0.50,0.75$, and 1 are applied to solar $\mathrm{PV}$ systems for prediction of deviations and variations.

\section{Numerical Results}

In the case of $f_{1}$ and $f_{2}$, the values of deviations of $f_{1}$ are 39.37 $\%$ in the lower bound and $52.02 \%$ in the upper bound from the crisp value of $f_{1}$. The values of deviations of $f_{2}$ are 33.14 $\%$ in the lower bound and $22.39 \%$ in the upper bound from the crisp value of $f_{2}$. These results indicate that uncertain input parameters are associated with collecting the amount of solar energy at a specified location and under seasonal characteristics as shown in Figure 5.

The uncertain input parameters of $S_{1}, S_{2}, S_{3}, S_{4}$, and $S_{8}$ are main factors that influence the values of deviations in $\mathrm{f}_{1}$. The other uncertain input parameters are less than $2 \%$ as shown in Figure 5(a). Four parameters of $S_{1}, S_{2}, S_{3}, S_{4}$, and $S_{8}$ contribute to the amount of average month incident solar energy. $S_{1}$ is the length of the cell receiver $\left(a_{r}\right)$, which is associated with $S_{2}\left(\theta_{c}\right)$. The value of the deviation of $a_{r}$ is the highest value for influencing the CPC PV performance because this factor helps determine the size of an array system. The value of $S_{2}$ contributes to the deviation of 7.92 


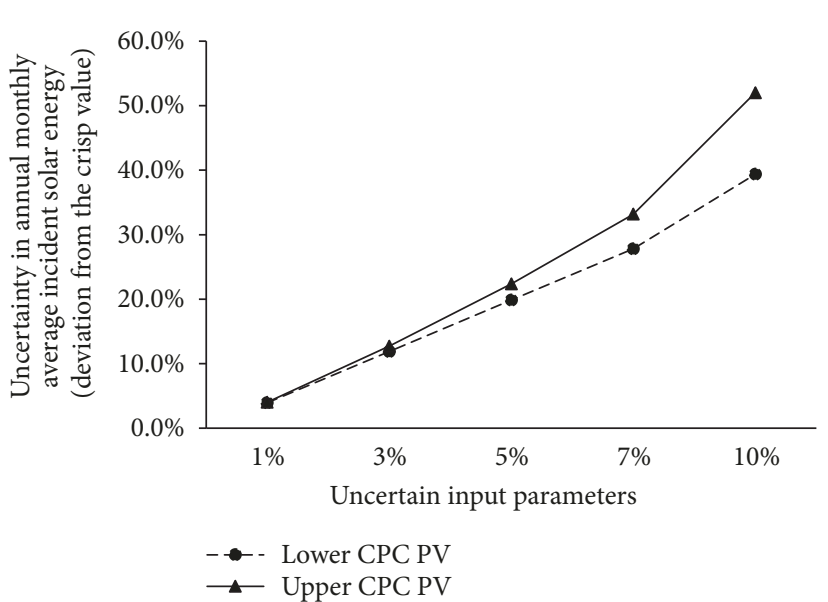

(a) Uncertainty in $\mathrm{f}_{1}$ of the solar CPC PV collector system

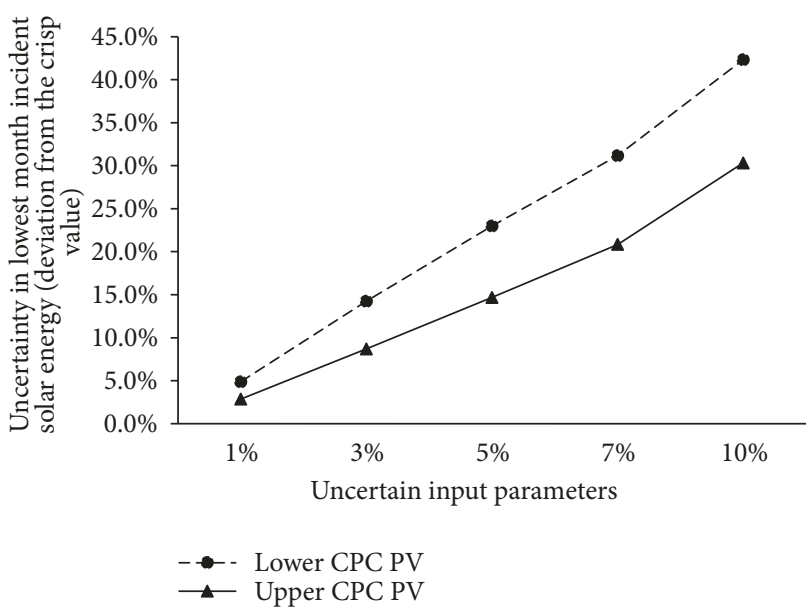

(b) Uncertainty in $\mathrm{f}_{2}$ of the solar CPC PV collector system

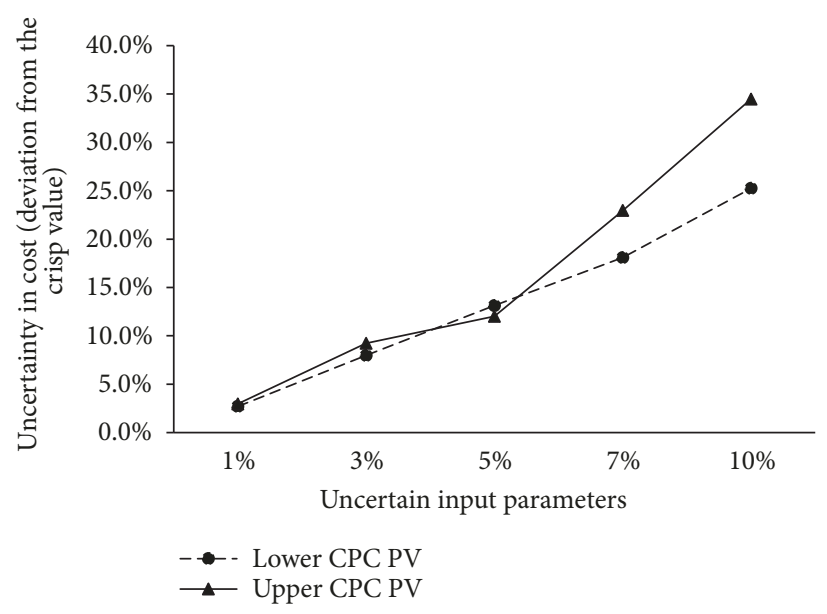

(c) Uncertainty in $\mathrm{f}_{3}$ of the solar CPC PV collector system

FIGURE 5: Variation of deviations of $\mathrm{f}_{1}, \mathrm{f}_{2}$, and $\mathrm{f}_{3}$ from the crisp value with respect to a fuzzy confidence interval.

$\%$ in the lower bound and $1.46 \%$ in the upper bound. In this case, $1.46 \%$ of the deviation from the crisp value of $S_{2}$ is lower than the deviation of the upper bound because this uncertain parameter influences the amount of solar energy, which means the lower bound section from the crisp value is more sensitive than the upper bound section. $\mathrm{S}_{3}$ of a solar CPC collector contributes to $10 \%$ of the deviation in both bounds. $\mathrm{S}_{8}$ is $10 \%$ in the lower bound and $9.98 \%$ in the upper bound.

In the case of $\mathrm{f}_{2}$, the deviation values are $42.34 \%$ in the lower bound and $30.34 \%$ in the upper bound from the crisp value of $\mathrm{f}_{2}$. The values of deviation in uncertain input parameters are similar to $f_{1}$ except for $\theta_{c}$ and $\beta$. The tilt angle $(\beta)$ is a critical factor in uncertain input parameters since the amount of incident solar energy fluctuates with varying tilt angles of an array due to Earth's axial tilt of $23.5^{\circ}$. Also, $\mathrm{S}_{5}$ of an uncertain parameter contributes to $3.47 \%$ of the deviation because the inclined arrays are sensitive to the distance between two adjacent rows with Earth's axial tilt angle at the lowest month (winter).

In the case of $\mathrm{f}_{3}$, the deviation values are $25.24 \%$ in the lower bound and $34.48 \%$ in the upper bound from the crisp value of $f_{3}$. Uncertain input parameters of $S_{1}, S_{2}, S_{3}, S_{4}$, and $S_{6}$ contribute to the results of the response of cost. $S_{1}$ and $\mathrm{S}_{2}$ of the uncertain parameters influence mainly $9.64 \%$ of the deviation in the lower bound and $10.24 \%$ in the upper bound because the cost of the CPC collector is estimated by the installation size (area) including the solar receiver, land, and reflectors. Figures 6 and 7 show the deviations of these three objective problems.

\section{Conclusion}

Fuzzy set analysis techniques used in solar CPC PV collector systems have been estimated. The results of fuzzy set analysis are gained by applying values of $\alpha$-cut level and fuzzy confidence intervals. This work illustrates the parametric study involved in the probabilistic performance of solar CPC PV collector systems. The optimal design of a solar CPC PV collector is investigated with a consideration of solar radiation with shading effects. The cell receiver and the acceptance angles of CPC units are the most striking critical factors that control the deviation values in upper bounds by $12.65 \%$ compared to lower bounds in annual season, but 


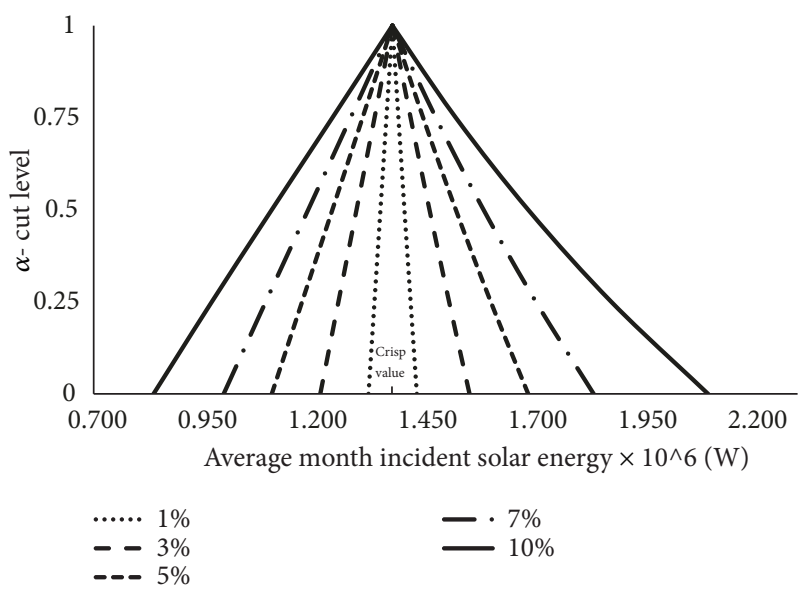

(a) Results of the influence on $f_{1}$

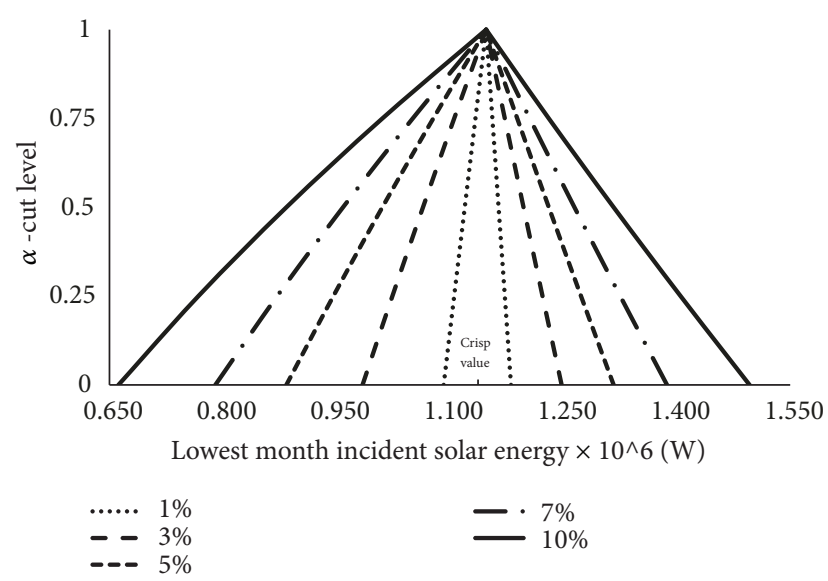

(b) Results of influence on $\mathrm{f}_{2}$

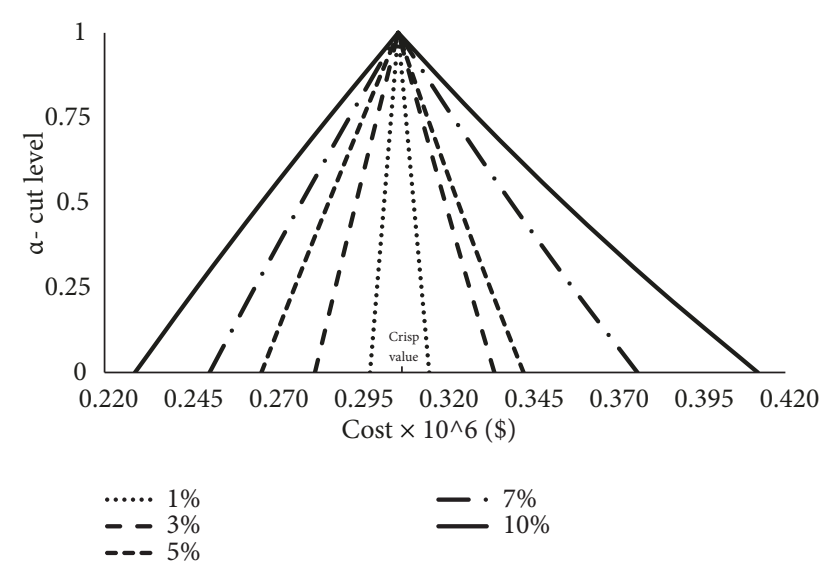

(c) Results of influence on $\mathrm{f}_{3}$

FIGURE 6: Variation of triangular shapes of $\mathrm{f}_{1}, \mathrm{f}_{2}$, and $\mathrm{f}_{3}$ with respect to a fuzzy set interval confidence.

the two design parameters, including angle of installation, dominate the deviation values in lower bounds by $10.75 \%$ compared to upper bounds. It is observed that the average monthly incident solar energy (annual season) and incident solar energy for lowest month (winter) are different from the deviation values from the crisp values. As seen in the present

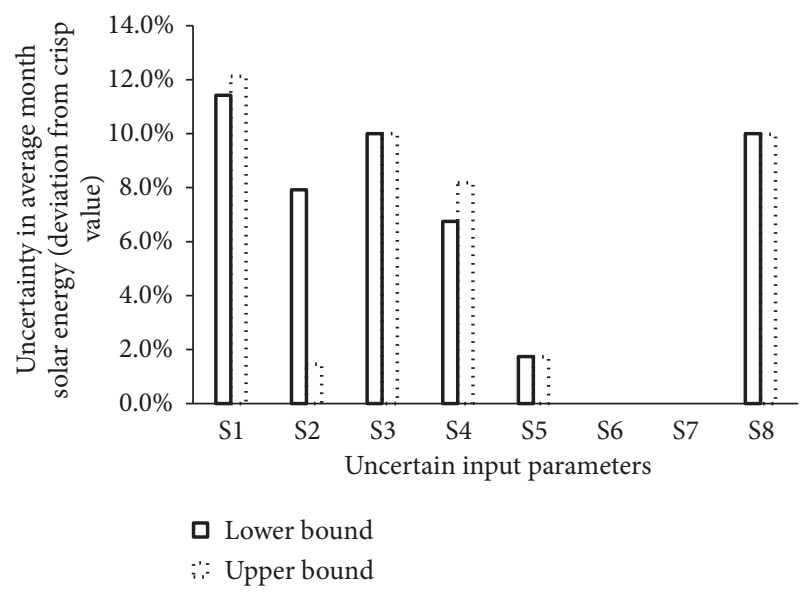

(a) Influence on average month incident solar energy of solar CPC PV collector with respect to uncertain input parameters

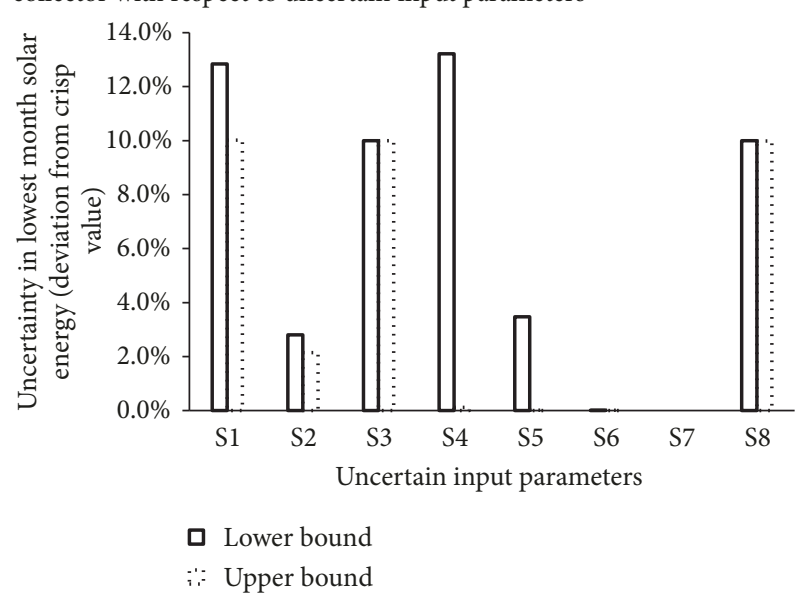

(b) Influence on lowest month incident solar energy of solar CPC PV collector with respect to uncertain input parameters

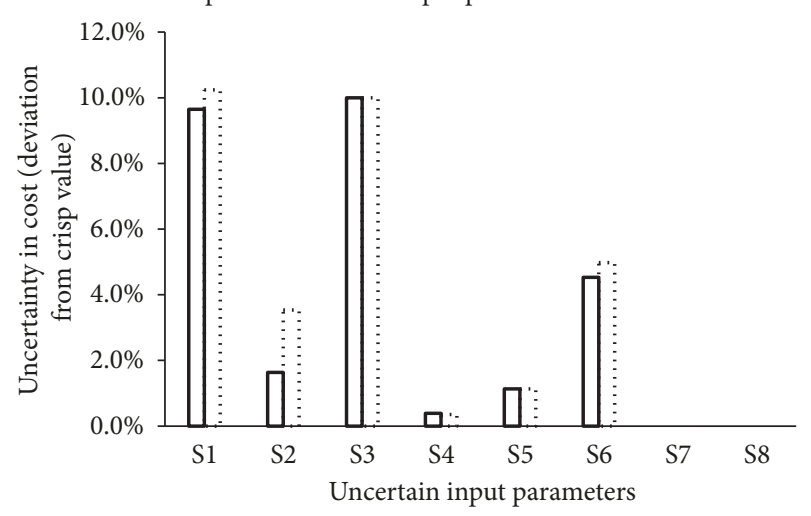

$$
\begin{aligned}
& \square \text { Lower bound } \\
& \because: \text { Upper bound }
\end{aligned}
$$

(c) Influence on cost of solar CPC PV collector with uncertain input parameters

FIgURE 7: Influence on cost of solar CPC PV collector with respect to uncertain input parameters.

results, when a solar CPC PV collector system is installed in an annual season, the difference between the deviation value of the lower bound section and the value of the upper bound 
section is smaller than in winter. The main reason is that the CPC installation is sensitive to seasonal characteristics, including solar radiation combined with shading effect from the adjacent rows. In the case of cost, upper bounds deviate by $9.24 \%$ compared to lower bounds, so that the size of an array, cell receiver, and reflector should be reflected in a cost estimate as seen in the results.

From a practical standpoint, variation values of design parameters of CPC units and PV collectors predict how variations from the absolute values of the optimal design parameters affect various deviations of the crisp values of objective performances. The variations can graphically describe multiple points along the transition range, from absolute possibility to absolute impossibility with a variety of shapes derived from fuzzy set theory descriptions on uncertainty. The results from the uncertain analysis of the design variables of single objectives contribute to the existing research in an impactful way by arming designers with a more economical and robust design approach based on customer requirements when they endeavor to design more efficient solar CPC PV collectors.

\section{Data Availability}

The data used to support the findings of this study are available from the corresponding author upon request.

\section{Conflicts of Interest}

The authors declare that they have no conflicts of interest.

\section{References}

[1] R. Winston and H. Hinterberger, "Principles of cylindrical concentrators for solar energy," Solar Energy, vol. 17, no. 4, pp. 255-258, 1975.

[2] A.-J. N. Khalifa and S. S. Al-Mutawalli, "Effect of two-axis sun tracking on the performance of compound parabolic concentrators," Energy Conversion and Management, vol. 39, no. 10, pp. 1073-1079, 1998.

[3] Y. Kim, G. Han, and T. Seo, "An evaluation on thermal performance of CPC solar collector," International Communications in Heat and Mass Transfer, vol. 35, no. 4, pp. 446-457, 2008.

[4] M. Antonelli, A. Baccioli, M. Francesconi, R. Lensi, and L. Martorano, "Analysis of a low concentration solar plant with compound parabolic collectors and a rotary expander for electricity generation," in Proceedings of the 68th Conference of the Italian Thermal Machines Engineering Association, ATI 2013, pp. 170-179, Italy, September 2013.

[5] M. Antonelli, A. Baccioli, M. Francesconi, U. Desideri, and L. Martorano, "Electrical production of a small size Concentrated Solar Power plant with compound parabolic collectors," Journal of Renewable Energy, vol. 83, pp. 1110-1118, 2015.

[6] M. Antonelli, M. Francesconi, P. Di Marco, and U. Desideri, "Analysis of heat transfer in different CPC solar collectors: A CFD approach," Applied Thermal Engineering, vol. 101, pp. 479489, 2016.

[7] D. R. Mills and J. E. Giutronich, "Asymmetrical non-imaging cylindrical solar concentrators," Solar Energy, vol. 20, no. 1, pp. 45-55, 1978.
[8] Y. Tripanagnostopoulos, P. Yianoulis, S. Papaefthimiou, and S. Zafeiratos, "CPC solar collectors with flat bifacial absorbers," Solar Energy, vol. 69, no. 3, pp. 191-203, 2000.

[9] Y. Tripanagnostopoulos, "Aspects and improvements of hybrid photovoltaic/thermal solar energy systems," Solar Energy, vol. 81, no. 9, pp. 1117-1131, 2007.

[10] N. Aste, C. del Pero, and F. Leonforte, "Water flat plate PVthermal collectors: A review," Solar Energy, vol. 102, pp. 98-115, 2014.

[11] M. Proell, P. Osgyan, H. Karrer, and C. J. Brabec, "Experimental efficiency of a low concentrating CPC PVT flat plate collector," Solar Energy, vol. 147, pp. 463-469, 2017.

[12] S. S. S. Baljit, H.-Y. Chan, V. A. Audwinto et al., "Mathematical modelling of a dual-fluid concentrating photovoltaic-thermal (PV-T) solar collector," Journal of Renewable Energy, vol. 114, pp. 1258-1271, 2017.

[13] T. K. Mallick, P. C. Eames, T. J. Hyde, and B. Norton, "The design and experimental characterisation of an asymmetric compound parabolic photovoltaic concentrator for building façade integration in the UK," Solar Energy, vol. 77, no. 3, pp. 319-327, 2004.

[14] J. Nilsson, H. Håkansson, and B. Karlsson, "Electrical and thermal characterization of a PV-CPC hybrid," Solar Energy, vol. 81, no. 7, pp. 917-928, 2007.

[15] C. Xu, Z. Chen, M. Li et al., "Research on the compensation of the end loss effect for parabolic trough solar collectors," Applied Energy, vol. 115, pp. 128-139, 2014.

[16] H. M. Bahaidarah, B. Tanweer, P. Gandhidasan, N. Ibrahim, and S. Rehman, "Experimental and numerical study on nonconcentrating and symmetric unglazed compound parabolic photovoltaic concentration systems," Applied Energy, vol. 136, pp. 527-536, 2014.

[17] L. A. Zadeh, "Fuzzy sets," Information and Computation, vol. 8, pp. 338-353, 1965.

[18] R. E. Bellman and L. A. Zadeh, "Decision-making in a fuzzy environment," Management Science, vol. 17, pp. B141-B164, 1970.

[19] Y. Xiong and S. S. Rao, "Fuzzy nonlinear programming for mixed-discrete design optimization through hybrid genetic algorithm," Fuzzy Sets and Systems, vol. 146, no. 2, pp. 167-186, 2004.

[20] O. E. Emam, "A fuzzy approach for bi-level integer non-linear programming problem," Applied Mathematics and Computation, vol. 172, no. 1, pp. 62-71, 2006.

[21] T.-F. Liang, "Fuzzy multi-objective production/distribution planning decisions with multi-product and multi-time period in a supply chain," Computers \& Industrial Engineering, vol. 55, no. 3, pp. 676-694, 2008.

[22] D. Dubey, S. Chandra, and A. Mehra, "Fuzzy linear programming under interval uncertainty based on IFS representation," Fuzzy Sets and Systems, vol. 188, pp. 68-87, 2012.

[23] J. Razmi, E. Jafarian, and S. H. Amin, "An intuitionistic fuzzy goal programming approach for finding pareto-optimal solutions to multi-objective programming problems," Expert Systems with Applications, vol. 65, pp. 181-193, 2016.

[24] D. Rani, T. R. Gulati, and H. Garg, "Multi-objective non-linear programming problem in intuitionistic fuzzy environment: Optimistic and pessimistic view point," Expert Systems with Applications, vol. 64, pp. 228-238, 2016.

[25] E. Jafarian, J. Razmi, and M. F. Baki, "A flexible programming approach based on intuitionistic fuzzy optimization and geometric programming for solving multi-objective nonlinear 
programming problems," Expert Systems with Applications, vol. 93, pp. 245-256, 2018.

[26] S. S. Rao, H.-G. Lee, and Y. Hu, "Optimal design of compound parabolic concentrator solar collector system," Journal of Mechanical Design, vol. 136, no. 9, 2014. 

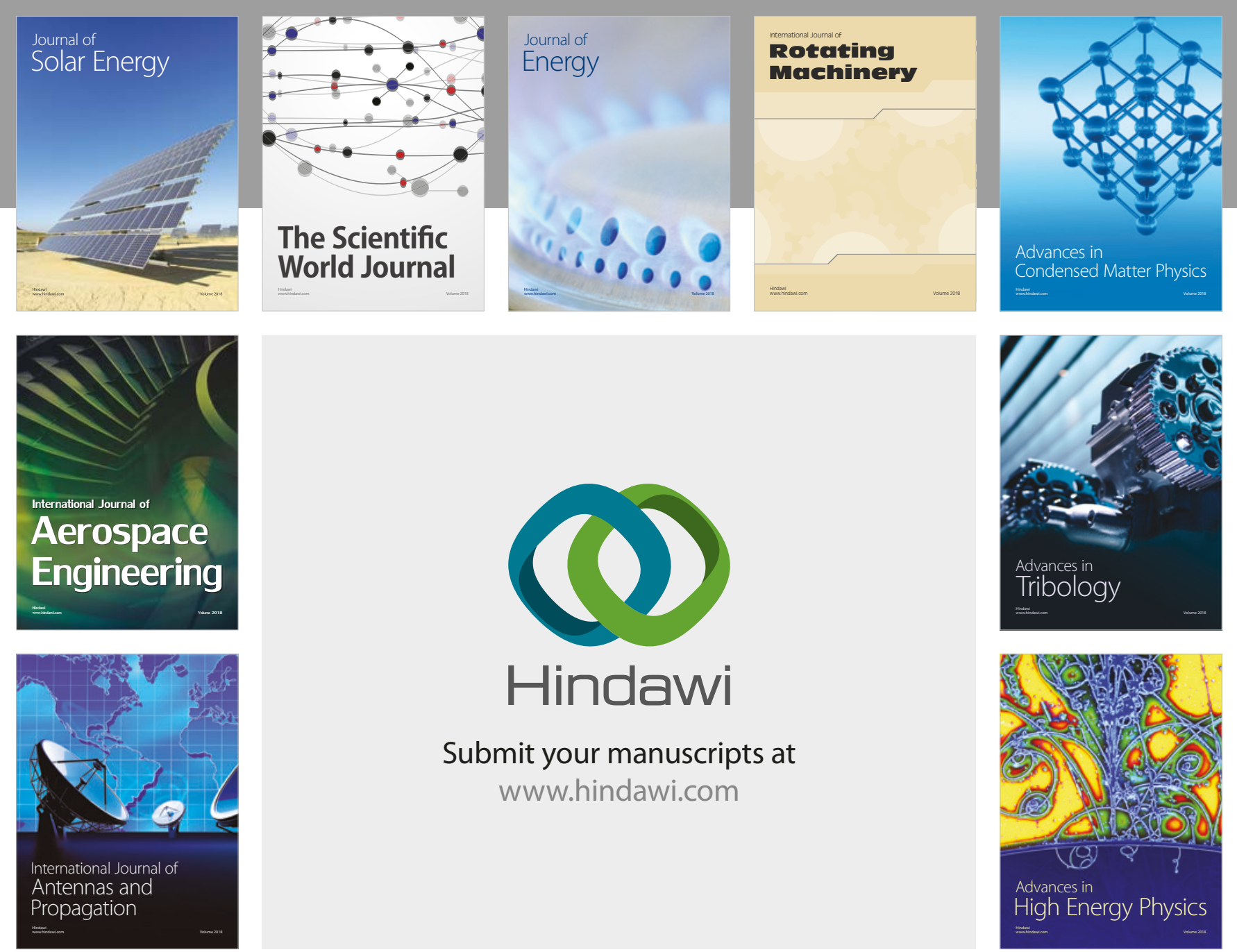

Submit your manuscripts at

www.hindawi.com
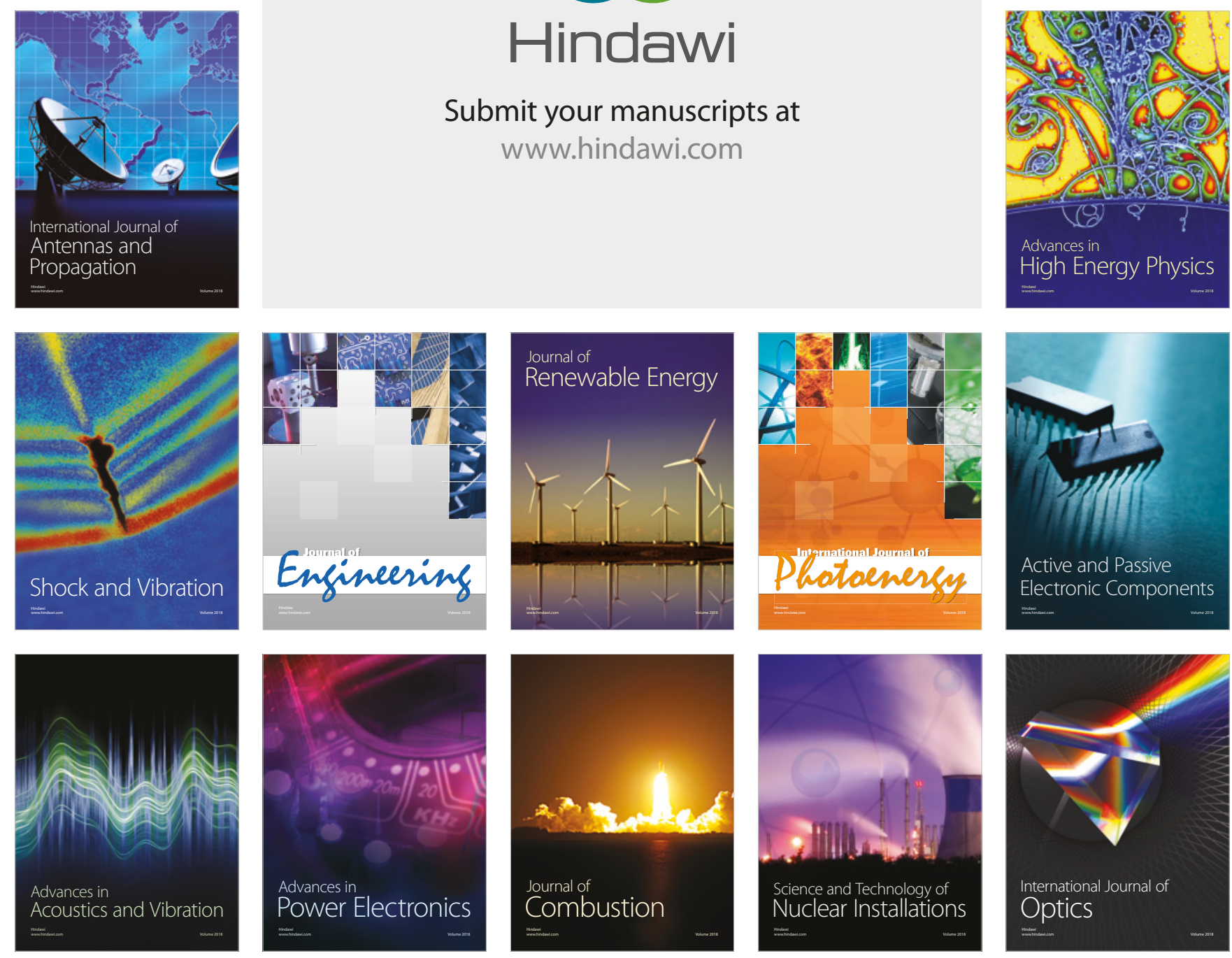